\title{
PID Algorithm and Fuzzy Control Algorithm in Step-less Speed Adjusting System Control with PLC
}

\author{
Yaolin Zhao \\ Sichuan Electric Vocational and Technical College, \\ Chengdu 610071, China \\ yaolinzhao@126.com
}

\begin{abstract}
-close loop step-less speed adjusting system is widely used in industrial control which is based on PLC and frequency converter. For getting better transient state function, and assure the speed adjusting smoothen and steady, PID and fuzzy control algorithm were independently used in the system controlling which is mentioned in this paper, and this system also can draw real-time curve .
\end{abstract}

Keywords- PLC; Step-less Speed Adjusting; PID;Fuzzy control

\section{INTRODUCTION}

To be an important branch of smart control, fuzzy control was abroad used in many specific control systems, especially in industrial control area. When the mathematics module can not be established accurately by system nonlinearity was strong and uncertainty was much, the fuzzy control can provide good solution to it.

Along with the unceasing development of PLC control technology, many manufacture provided advanced program to realize fuzzy control, for satisfying the control requirement that PID control can not solve. So, to use fuzzy control in PLC control system was heat point in recent research. PID and fuzzy control algorithm were independently used in the system controlling which is mentioned in this paper, and it can get that fuzzy control can make this system better in transient state function.

\section{COMPOSITION OF SYSTEM}

This system used frequency converter to control motor to be started, stop, forward rotate, back rotate and speed adjusting with PLC, and the rotate speed information can collected by photoelectric encoder. After PLC get the information, it used PID control program or fuzzy control program to create new control signal, and output to frequency converter, for making sure that the speed adjusting action on motor was smooth and quickly.

To monitor the control process, used configuration software MCGS to build up monitoring surface, and draw real-time curve window to show setting signal curve, frequency converter out signal curve and feedback signal.

\author{
Dapeng Xing \\ Sichuan Electric Vocational and Technical College \\ Chengdu 610071, China
}

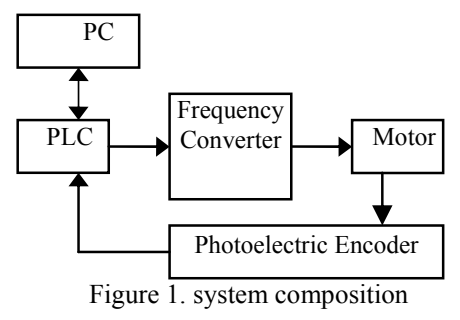

\section{A. Configuration interface building}

As Figure. 2 shows, when this system was running, firstly, setting the preset value in the setting window, and then click the "SET" button to transit the value to PLC resistor. Next, click the button "forward rotate" or "back rotate" to run the motor. During the running process, the real-time curve can be showed after click "show curve" button.

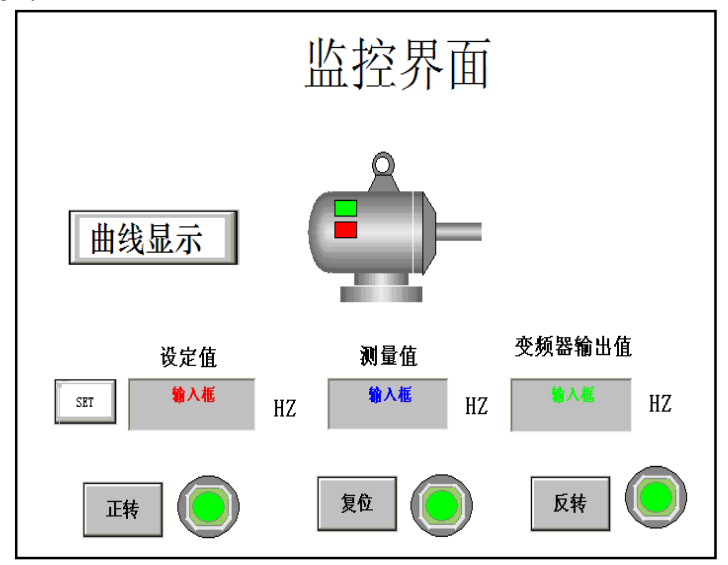

Figure 2. control interface

PC which is built Configuration software, communicated to PLC through RS232 interface. With setting variable value, device setting and channel connection, PC can exchange data with PLC.

\section{B. Frequency converter setting}

It used PWM technology to control converter in Stepless speed adjusting, one channel PWM was created by PLC and output to converter to changing the output pulse width of converter, so the speed of motor can be adjusted. The 
relationship of the PWM of PLC and frequency signal which converter output was as below:

Frequency instructs value $=$

$(\mathrm{ON}$ time/period of $\mathrm{PWM}) \times$ maximum output frequency

In this formula, the maximum output frequency was setting in converter (100 Hz was used here), by change the duty ratio of PLC output PWM signal, the speed of motor can be controlled.

\section{PLC Program design}

\section{1) PID program design}

In PLC program instruction, PID instruction was F355 (PID), this instruction needed 11 parameter setting registers and 19 data registers were needed to program calculate. The program in this paper, used DT10-DT39 to be PID instruction area, and used DT10-DT20 to be parameter setting area.

The program was as Figure. 3 shows:

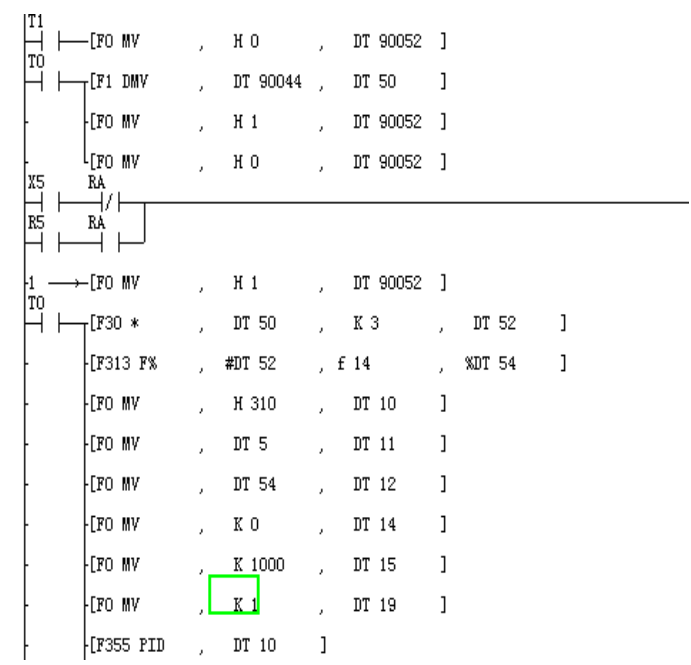

Figure 3. PID Algorithm Routine

\section{2) Fuzzy control program design}

al circuit was mainly composed of CPLD and single-chip. CPLD was responsible for acquiring the output signal of comparator, due to its acquiring signal rate was at the level of nanosecond, and the real signal was maintained for more than $10 \mathrm{~ns}$, so CPLD can judge a signal was laser pulse signal or background light which had a maintain time larger than laser pulse by there maintaining time, to reduce the rate of false alarm more. When the signal was validated as pulse signal, it would be transferred to single-chip for direction identify, the direction information was determined according to the internal query program. The method was that using 12 $\mathrm{I} / \mathrm{O}$ pins the address corresponding to detectors. When more than one pin received signal, then it corresponds to the center position of their overlap zone. As there were 2 detectors at one floor, and 4 detectors at two floors can make response to laser signal at the same time, so the instance of receiving signal were finite. Code every possible instance, when there was laser strikes, the single-chip would send the code to display module via serial port according to pins' information.

Fuzzy control program was designed by next steps:

(1) Assured input and output fuzzy variable value.

(2) Built fuzzy control status list.

(3) Program the application program

Write the quantized factors of input and output variable value to the appointed data registers, and then calculated the real speed of motor with using the pulse quantity which collected by photoelectric encoder. Compared it with the object value to get the speed discrepancy e and speed discrepancy changing value $\mathrm{e}_{\mathrm{c}}$, multiplied $\mathrm{e}$ and $\mathrm{e}_{\mathrm{c}}$ to quantized factors independently to get the new output value. The flow of the program was as Figure.4 showed [5] [6].

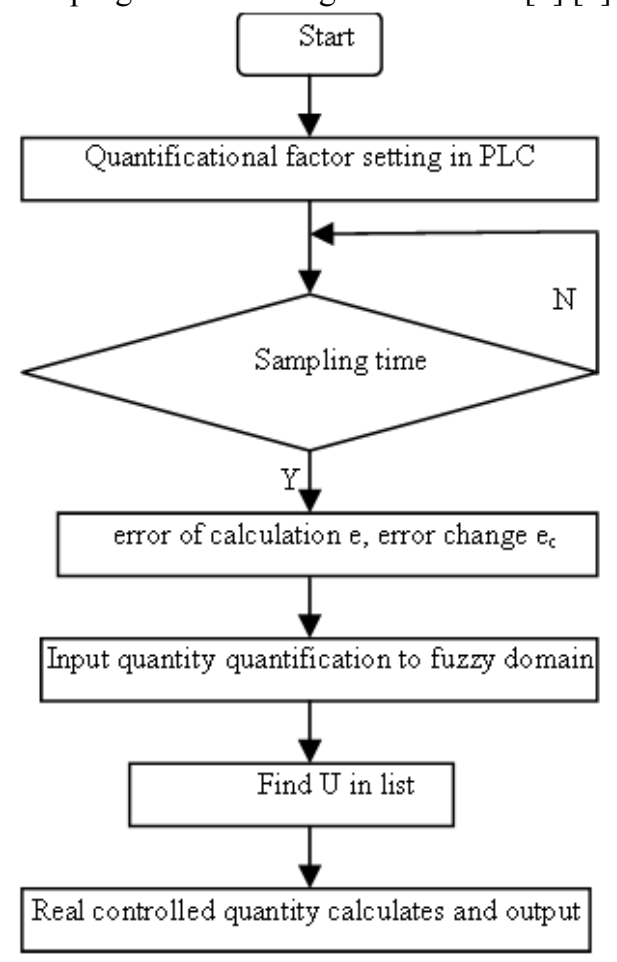

Figure 4. fuzzy algorithmic approach flow

Polling list was the control algorithm summary sheet of control system; it was designed to be subprogram of main program. When the system was running, main program look up the list by call subprogram. During a control period, main program multiplied $\mathrm{e}(\mathrm{k})$ which was real collected to quantized fact $\mathrm{Ke}$, and $\mathrm{e}_{\mathrm{c}}(\mathrm{k})$, which was gotten by calculated, multiplied to quantized factors Kc, and the E(i)和 EC(i) in domain of discourse can get by look up polling list, and then look up the relationship of them to get input value $U$, multiplied $\mathrm{U}$ and quantized factors $\mathrm{Ku}$, at last, the output control value can be gotten. 


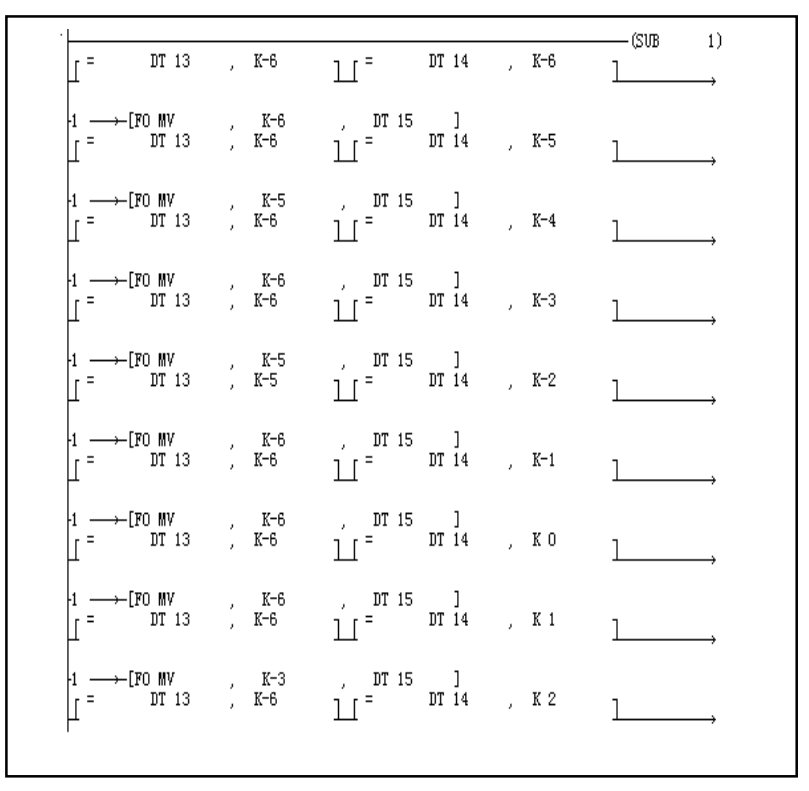

Figure 5. fuzzy algorithmic approach program

\section{REAL-TIME CURVES}

The curves that PID control and fuzzy control created were showed as Figure.6 a and b, it used history record function of configuration software. By capered the two curve, it can find than, to this system, fuzzy control can perform better, cause the fuzzy control can make the speed adjusting more quickly and smooth, the transient state function of this system was better.

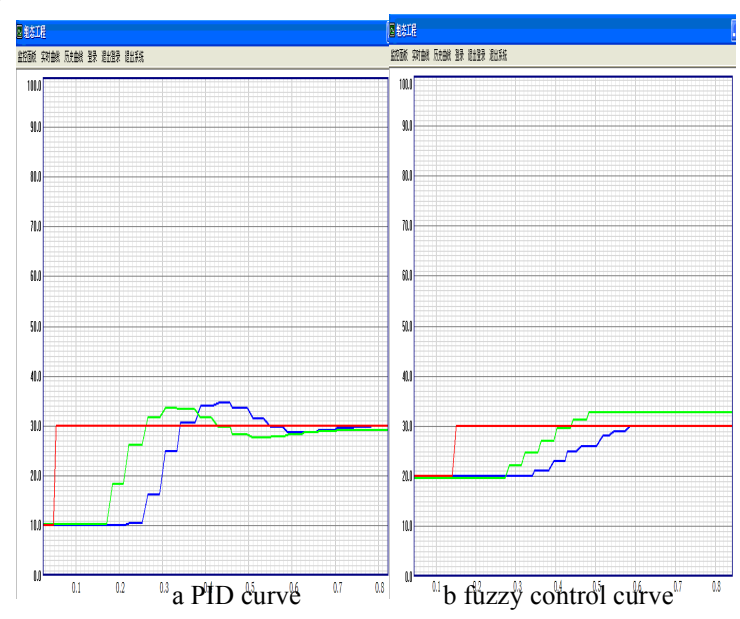

Figure 6. real-time control curve

\section{CONCLUSIONSE}

It realized the step-less speed adjusting with using PID control and fuzzy control based on PLC and frequency converter. These two ways both can make the speed adjusting of motor get quickly and smooth, assured the steady function of system. Built the control surface with using configuration software and the real-time curve can be show in this surface. With using this surface, the monitored work got simpler and more intuitively. According to the research, provided two solution to build step-less speed adjusting system, and the two solutions had good practical applicability.

\section{REFERENCES}

[1] DING Jia-jia; CHEN Ming-wei. Design and Realization of Measurement Scale Control System Based on Fuzzy-adaptive Control [J]. Control and Instruments in Chemical Industry. 2010, 37(9): 72 74

[2] SUN Ling; HONG Xue-feng. Design of constant pressure water supplying system based on PLC\&fuzzy PID [J]. Automation \& Instrumentation.2010, 03 (6):35-39

[3] LUO Tian-zi, CHEN Wei-bing, ZOU Hao-jie, LI Zhong-liang. A Study of Fuzzy Incremental PID Control Algorithm for Linear Motor [J]. Measurement \& Control Technology 2011，30（2）: 61-64

[4] ZHANG Bao-fu; MU Xi-hui; DU Feng-po; YU Jian-hua. A Wheel Angle Measuring and Displaying System Based on Photoelectric Encoder and PLC [J]. Machinery \& Electronics.2009 (7):62-64.

[5] Li Lin. The Applications of Fuzzy Control in Sewage Disposal [J]. Industrial Control Computer, 2004, 17 (11):16-17

[6] Yan MinSong Zhong WeiBi, and Liu Kun, The PLC System of Egg Powder Treatment Based on Fuzzy Control Algorithm,the 4th International Conference On Fuzzy Systems and knowledge Diseovery (FsKD’07) [C], 2007, Volume 4:530-534

[7] HUANG Yong-hong; JI Yu-hui; YANG Dong. Design and Realization of Variable Frequency and Speed Regulation of Motor Experiment System Based on PLC [J]. ElectricMachines \& Control Application.2007 , 34 (10): 40-43. 